\title{
Design and Analysis of Optimal Controllers for Grid Connected Inverters for Photovoltaic Applications
}

\author{
Gussan Mufti ${ }^{1,2}$, Mohsin Jamil ${ }^{1}$, Raheel Afzal ${ }^{1}$, Muhammad Arifeen Ali ${ }^{1}$ \\ and Asim Waris ${ }^{1}$ \\ ${ }^{1}$ National University of Sciences and Technology (NUST), H-12 Islamabad, \\ Pakistan \\ ${ }^{2}$ Bahria University Islamabad \\ gussanmufti@ces.nust.edu.pk,mohsin@smme.nust.edu.pk
}

\begin{abstract}
The focus of this research article is to model and analyze optimal controllers for a two level, pulse width modulated, grid connected inverter using Matlab. The Proportional Resonant controller and Linear Quadratic Regulator are being investigated. The controllers are designed such that their performance is satisfactory. The simulation results are presented to illustrate the performance of the designed controllers under different grid conditions.
\end{abstract}

Keywords: Grid Connected Inverter, Current Control, Linear Quadratic Regulator, Proportional Resonant Controller, Photovoltaic Systems

\section{Introduction}

The power quality, importance increases in Renewable Energy Systems (RES) especially PhotoVoltaic (PV) systems. The increase in the number of the Photovoltaic systems connected to the grid has increased the importance for the implementation of a unified standard for these installations. In this regard, the standards followed are IEEE 1547 and IEEE929 along with IEC 612727.According to these standards, the overall allowable limit of the Total Harmonic Distortion (THD) is 5\%. The odd harmonics from $3^{\text {rd }}$ to $9^{\text {th }}$ should be under $4 \%$ each and allowable limit of the odd harmonics from $11^{\text {th }}$ to $15^{\text {th }}$ must be $2 \%$.

These standards present a challenge to the design engineers to develop current control systems that is able to not only meet these requirements, but is also capable of rejection of the grid variation in order to ensure a reliable operation of the installed PV system according to the prescribed standards of IEEE.

Figure 1. shows a sinusoidal waveform with the fundamental frequency of $50 \mathrm{~Hz}$ and a distorted waveform in the presence of $3^{\text {rd }}, 5^{\text {th }}$ and $7^{\text {th }}$ harmonics. As seen from the figure that the presence of harmonics can result in a reduction of the power quality. The conventional controllers fail to mitigate the harmonics and thus there arises a need to adopt advance current controllers that can effectively remove the harmonics[1-16].

The main objective of this article is to design a grid connected PVS and investigate the performance of Proportional Resonant (PR) and Linear Quadratic Regulator (LQR) by simulating the systems in Matlab. The performance of $\mathrm{CCs}$ is analyzed under high distortions using the axioms of control theory. 


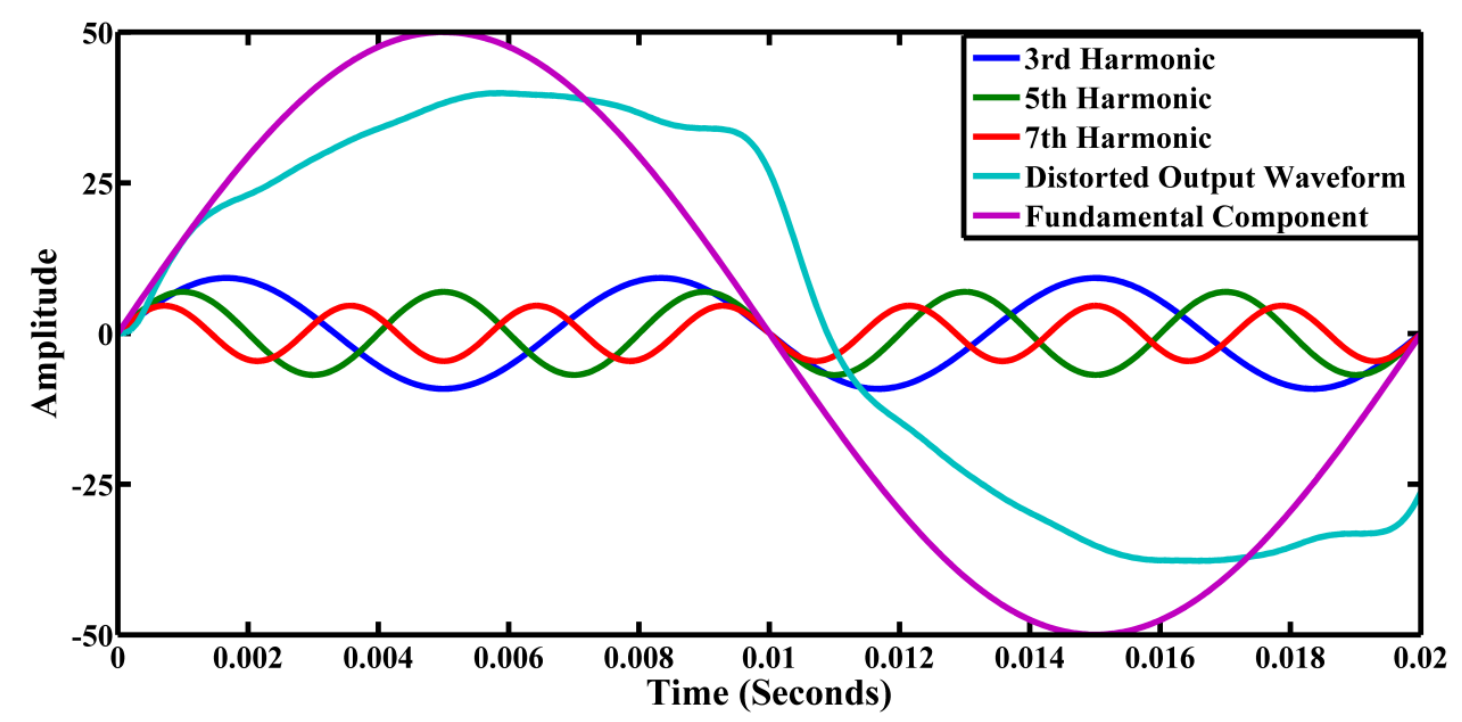

Figure 1. Current Waveform Under Harmonics

\section{Mathematical Modelling of the Grid Connected System}

The control system forms an integral part of the PVS[1][2][3][4]. The control of the renewable energy system has two main parts. The grid side control and the input power control[6]. The following analysis of the single phase linear model of the converter is given by assuming that the system is balanced and there exists no phase interaction between the phases.

$$
\begin{aligned}
& V_{\text {input }}-V c=L g \frac{d I g}{d t} \\
& I c=C \frac{d V_{C}}{d t}
\end{aligned}
$$

$I c=I g-I u$

$V c-V u=L_{2} \frac{d I u}{d t}$

The expression for the output current can be derived by using the above equations as shown below;

$$
\begin{aligned}
& \text { Putting (2) in (3) } \\
& C \frac{d V_{C}}{d t}=I g-I u \\
& I g=\frac{d V_{C}}{d t}+I u
\end{aligned}
$$


Differentiating (5)

$$
\frac{d I g}{d t}=\frac{d}{d t}\left[C \frac{d V_{C}}{d t}\right]+\frac{d I u}{d t}
$$

Putting (6)in (1)

$$
\begin{aligned}
& \text { Vinput }-V c=L g\left[\frac{d}{d t} C \frac{d V_{C}}{d t}+\frac{d I u}{d t}\right] \\
& \text { Vinput }-V c=L g C \frac{d^{2} V_{C}}{d t^{2}}+L g \frac{d I u}{d t}
\end{aligned}
$$

Vinput $=\operatorname{LgC} \frac{d^{2} V_{C}}{d t^{2}}+L g \frac{d I u}{d t}+V c$

Subsitute the value of $V c=L u \frac{d I u}{d t}+$ Vutility in (7)

$$
\begin{aligned}
& \text { Vinput }=L g C \frac{d^{2}}{d t^{2}}\left(L u \frac{d I u}{d t}+V u t i l i t y\right)+L g \frac{d I u}{d t}+V c \\
& \text { Vinput }=\operatorname{Lg}\left[\frac{d^{2} C}{d t^{2}}\left(L u \frac{d I u}{d t}+V u t i l i t y\right)+\frac{d I u}{d t}\right]+V c \\
& \text { Vinput }=L g\left[\frac{d^{2} C}{d t^{2}}\left(L u \frac{d I u}{d t}+V u t i l i t y\right)+\frac{d I u}{d t}\right]+L u \frac{d I u}{d t}+V u \\
& \text { Vinput }=L g\left[\frac{d^{2}}{d t^{2}} C V u t i l i t y+C L u \frac{d^{3} I u}{d t^{3}}+\frac{d I u}{d t}\right]+L u \frac{d I u}{d t}+V u t i l i t y \\
& \text { Applying Laplace Transform } \\
& \text { Vinput }=L g\left[s^{2} C V u t i l i t y+L u C s^{3} I u+s I u\right]+L u s I u+V u t i l i t y \\
& \text { Vinput }=L g s^{2} C V u t i l i t y+L g L u C s^{3} I u+L g s I u+L u s I u+V u t i l i t y \\
& \text { Vinput }=L g s^{2} C V u t i l i t y+\left(L g L u C s^{3}+L g s+L u s\right) I u+V u t i l i t y \\
& \text { Vinput }=V u t i l i t y\left(L g s^{2} C+1\right)+I u\left(L g L u C s^{3}+L g s+L u s\right)
\end{aligned}
$$




$$
\begin{aligned}
& I u\left(L g L u C s^{3}+L g s+L u s\right)=V i n p u t-V u t i l i t y\left(L g s^{2} C+1\right) \\
& I u\left(L g L u C s^{3}+(L g+L u) s\right)=V i n p u t-V u t i l i t y\left(L g s^{2} C+1\right) \\
& I u=\frac{1}{\left(L g L u C s^{3}+(L g+L u) s\right)} V i n p u t-\frac{\left(L g s^{2} C+1\right)}{\left(L g L u C s^{3}+(L g+L u) s\right)} \text { Vutility }
\end{aligned}
$$

If the gain for the PWM block is assumed to be unity then the relationship between the output current and reference input current is given by the following transfer function;

$$
\begin{gathered}
I_{u}=\frac{G z(\mathrm{~s})}{1+G z(\mathrm{~s})} I_{\text {ref }}-\frac{G_{\text {plant }}(s)}{1+G z(\mathrm{~s})} \text { Vutility } \\
G z(\mathrm{~s})=G_{\text {plant }}(s) * G_{\text {controller }}(s)
\end{gathered}
$$

To make the system more realizable and closer to real time scenarios a disturbance function can be introduced which is given by the following equation as

Disturbance $(s)=V_{\text {utility }}\left(L_{g} C s^{2}+K_{c} C s+0.5\right)$

The system values that are used for the Matlab simulation are given in the Table 1.

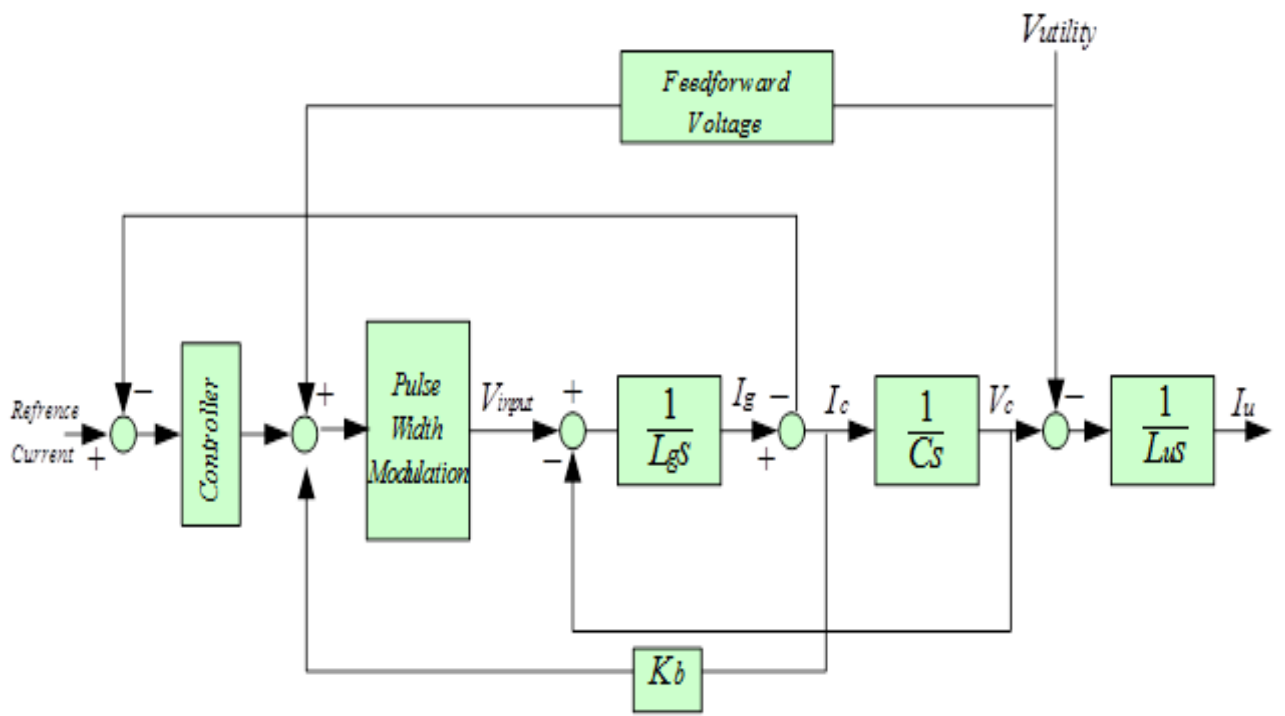

Figure 2. Control Structure of the Grid Connected Inverter

Table 1. Component Values of the Grid Connected System

\begin{tabular}{|c|c|c|c|}
\hline $\begin{array}{c}\text { Sr. } \\
\text { No. }\end{array}$ & Electrical Parameter & Symbol & Value \\
\hline 1 & Peak Voltage of the Grid & $V_{\text {peak }}$ & $230 \mathrm{~V}(\mathrm{rms})$ \\
\hline 2 & DC link voltage & $V_{d c}$ & $800 \mathrm{Vdc}$ \\
\hline 3 & Grid inductor & $L_{g}$ & $350 \mu \mathrm{H}$ \\
\hline 4 & Utility inductor & $L_{u}$ & $50 \mu \mathrm{H}$ \\
\hline 5 & Capacitor & $C_{s}$ & $22.5 \mu \mathrm{F}$ \\
\hline 6 & Switching frequency & $f_{s}$ & $10 \mathrm{kHz}$ \\
\hline 7 & Grid Frequency & $f_{g}$ & $50 \mathrm{~Hz}$ \\
\hline 8 & Output Current & $I_{\text {out }}$ & $50 \mathrm{~A}$ \\
\hline
\end{tabular}




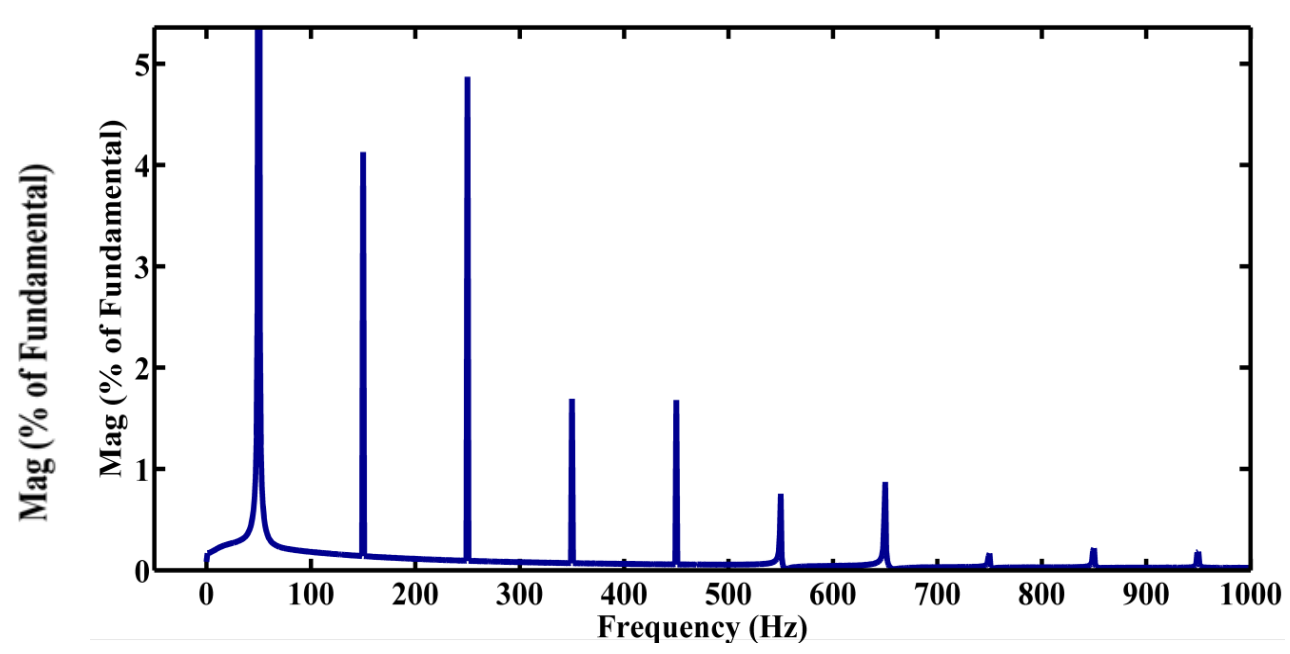

Figure 3. Frequency Spectrum for PI Controller having THD=8.05\%

\section{Matlab Simulation Results}

\subsection{Frequency Response of PI Controller Under Harmonic Distortions}

Figure 3 shows the Fast Fourier Transform (FFT) analysis of the PI controller when the a THD of $2.74 \%$ was introduced in the utility voltage. The THD values at the output was found to be $8.05 \%$. Though it was able to reduce the THD values, but it failed the ANSI-IEEE recommended THD values which is $5 \%$. The odd harmonic at $250 \mathrm{~Hz}$ was the highest harmonic that the PI controller failed to suppress.

\subsection{Frequency Response of Optimal Controller Under Harmonic Distortions}

A novel Proportional Resonant (PR) controller was designed using Harmonic Compensators (HC) for higher order harmonics. The frequency spectrum analysis was obtained as shown in Figure.

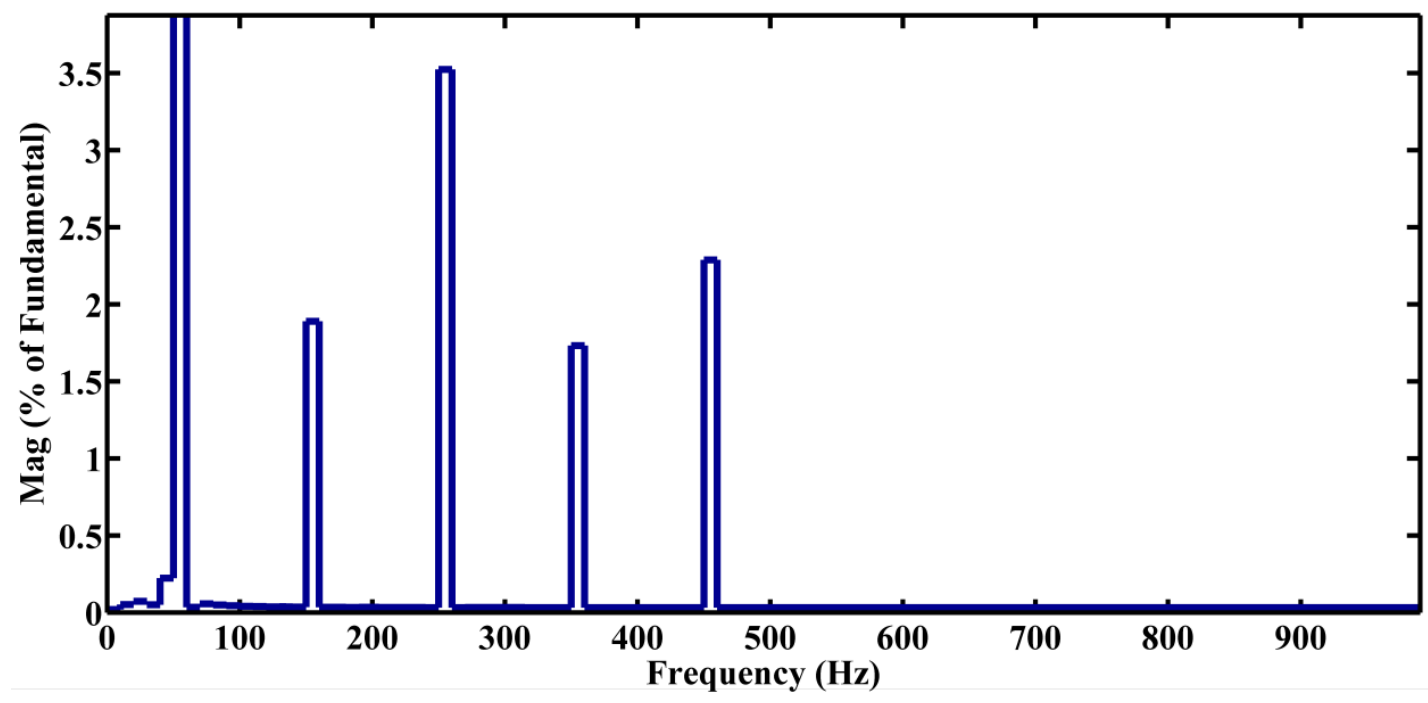

Figure 4. Frequency Spectrum for Proportional Resonant Controller having THD $4.96 \%$ 
As shown in the Figure that the PR controller was able to achieve the prescribed limits of ANSI-IEEE of 5\% of THD. The highest harmonic was observed at $250 \mathrm{~Hz}$ (5th Harmonic) with the magnitude of $3.4 \%$ of the fundamental frequency. By using the PR controller THD is $0.4 \%$ less than the prescribed limits of recommended THD values. As it was stated earlier, the increase in the performance of the controller was achieved at the cost of the increased complexity at the same time.

\subsection{Frequency Spectrum Analysis of Linear Quadratic Regulator (LQR)}

The frequency spectrum analysis of the conventional controllers showed that they were unable to meet the operating requirements. In order to reduce the THD to the acceptable limits a Linear Quadratic Regulator (LQR) was designed. The state space model was achieved by using the state space block of Matlab. The values of the gain are given by

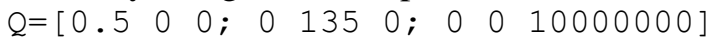

$\mathrm{R}=0.3$

Figure 5. shows the frequency spectrum of a LQR. The LQR though successively reduced the THD to $4.51 \%$. It is important to note that adjusting the gains of a LQR controller is an iterative process and there is no hard fast rule that states how they should be adjusted. After a trial and error process the LQR controller was being adjusted so that it can reduce the THD to $4.51 \%$ as compared to $8.05 \%$ of a PI controller. A further adjustment in the gains may have reduced the THD limits further, but it results in the severe performance degradation of the LQR. Therefore, the gain of an LQR was being kept such that it achieves a THD of $4.51 \%$.

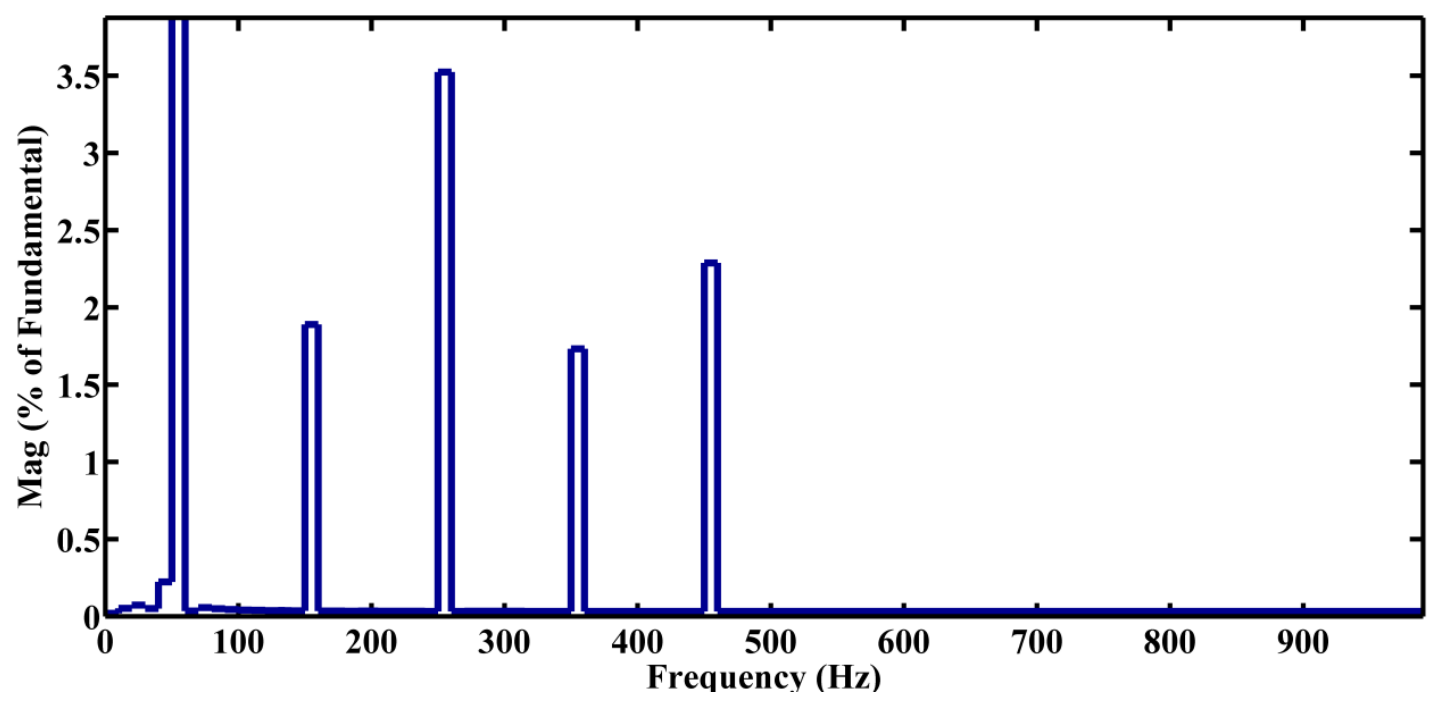

Figure 5. Frequency Spectrum for LQR having THD 4.51\%

\section{Conclusion}

This paper presents an analysis of the optimal controllers for Utility connected PV systems. The results show that the allowed IEEE THD values are 5\% and the only controllers that are able to keep the THD values under this limit are optimal controllers $\mathrm{PR}$ and LQR. The PI controller is easier to implement, but they are prone to inherent limitations due to which they fail to perform according to the standards of ANSI-IEEE under distortions. In the future, further investigation of both controllers on Real Time Digital Simulator (RTDS) would be done to verify the results obtained from Matlab. 


\section{References}

[1] M. Trifkovic, M. Sheikhzadeh, K. Nigim and P. Daoutidis, "Modeling and Control of a Renewable Hybrid Energy System With Hydrogen Storage", IEEE Trans. Control Syst. Technol., vol. 22, no. 1, (2014), pp. 169-179.

[2] M. Jamil, R. Arshad, U. Rashid, S. O. Gillani, Y. Ayaz and M. N. Khan. "Robust Repetitive Current Control of Two Level Utility Connected Converter using LCL Filter", Arabian Journal for Science and Engineering. ISSN: 1319-8025., vol 40, Issue 9, (2015), pp.2653-2670.

[2] A. Chauhan and R. P. Saini, "A review on Integrated Renewable Energy System based power generation for stand-alone applications: Configurations, storage options, sizing methodologies and control", Renew. Sustain. Energy Rev., vol. 38, (2014), pp. 99-120.

[3] Y. Hong, R. Waters, C. Boström, M. Eriksson, J. Engström and M. Leijon, "Review on electrical control strategies for wave energy converting systems", Renew. Sustain. Energy Rev., vol. 31, (2014), pp. 329342.

[4] M. A. Abusara, M. Jamil and S. M. Sharkh, "Repetitive current control of an interleaved grid-connected inverter", $20123^{\text {rd }}$ IEEE Int. Symp. Power Electron. Distrib. Gener. Syst. , (2012), pp. 558-563.

[5] D. N. Zmood, S. Member and D. G. Holmes, "Stationary Frame Current Regulation of PWM Inverters With Zero Steady-State Error", vol. 18, no. 3, (2003), pp. 814-822.

[6] M. Jamil, R. Arshad, U. Rashid and Y. Ayaz, "Design and analysis of repetitive controllers for grid connected inverter considering plant bandwidth for interfacing renewable energy sources", Proceedings of 2014 IEEE International Conference on Renewable Energy Research and Applications Application (ICRERA), (2014).

[7] M. Jamil, S. M. Sharkh, M.A. Abusara and R. J. Boltryk. "Robust Repetitive Controller Feedback Control of a Three- Phase Grid Connected Inverter", in $5^{\text {th }}$ IET International Conference on Power Electronics and Drives, United Kingdom, (2010).

[8] M. Jamil, B. Hussain, S. M. Sharkh, M. A. Abusara and R. J. Boltryk, "Microgrid Power Electronic Converters: State Of The Art and Future Challenges", Proceedings of the $44^{\text {th }}$ International Universities Power Engineering Conference (UPEC), U.K, (2009).

[9] G.M.Mufti, M.Jamil, A. Waqas and M.U. Ali, "Two Level Voltage Source Grid Connected Inverter for Solar Photovoltaic System", International Journal of Control and Automation, vol 8, no. 10, (2015), pp. 391-398.

[10] M. Jamil, "Design and Analysis of Odd-Harmonic Repetitve Control for Three-Phase Grid Connected Voltage Source Inverter", Review on Electrical Engineering (Przeglad Electrotechniczny), ISSN: 00332097, vol. 1a, (2013), pp. 292-95.

[11] M. A. Abusara, M. Jamil and S. M. Sharkh, "Repetitive Current Controller for Interleaved GridConnected Inverters", 3rd International Symposium on Power Electronics for Distribution Generation Systems, Denmark, (2012).

[12] M. Jamil, "Repetitive Current Control of Two-Level and Interleaved Three-Phase PWM Utility Connected Inverters", PhD Thesis, Faculty of Engineering and the Environment. University of Southampton, United Kingdom, (2012).

[13] M. Haseeb, M. Jamil, M. Faisal and F. Firdousi, "Analysis of Three-Phase Two-Level PWM Inverter with LCL Filter using Classical Controllers for Renewable Energy Sources", Proceedings of International Conference on Energy and Sustainability, NED UET Karachi, (2013), pp.63 - 67.

[14] M. Jamil, S. M. Sharkh and M. A. Abusara, "Current Regulation of Three-Phase Grid Connected Voltage Source Inverter Using Robust Digital Repetitive Control”, International Review of Automatic Control (Theory and Applications), vol. 4, (2011).

[15] M. Jamil, "DSP Based Hardware Implementation of Repetitive Current Controller for Interleaved Grid Connected Inverter", Review on Electrical Engineering (Przeglad Electrotechniczny), ISSN: 00332097, vol.2a, (2013), pp. 251-55.

[16] S.S.Khawaja, M. Jamil,Q. Awais,U.Asgher and Y.Ayaz, "Analysis of Classical Controller by Variation of Inner Loop and Controller Gain for Two-level Grid-connected Converter", Indian Journal of Science and Technology, ISSN:0974-6846, vol 8, no. 20, (2015).

\section{Authors}

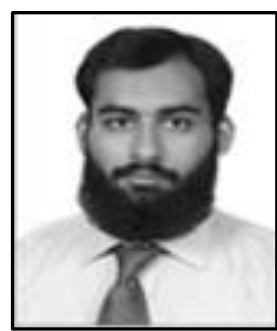

GussanMufti, he did his master's degree from National University of Sciences and Technology (NUST) in Energy Systems Engineering. He did his bachelors from University of Engineering and Technology Peshawar. He is currently serving as a lecturer in Bahria University Islamabad.His research interests include grid connected inverters and power system analysis. 


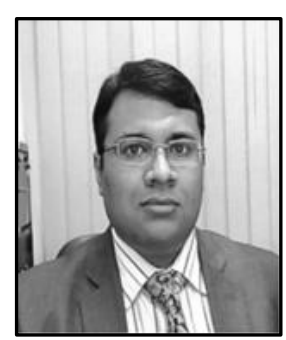

Mohsin Jamil, he is serving as Assistant Professor and Deputy Head of Department in the department of Robotics and Artificial Intelligence at National University of Sciences and Technology, Pakistan. He completed his $\mathrm{PhD}$ in Electrical Engineering from University of Southampton, U.K. His research area is Control Systems/Power Electronics.

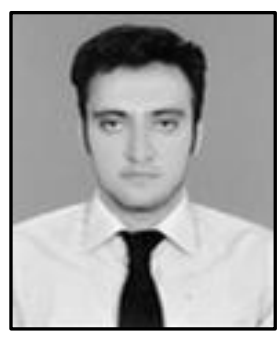

Raheel Afzal, he is a MS Energy Systems Engineering student at U.S-Pak Centre for Advance Studies in Energy, NUST. He has completed his BS Electronic Engineering from IUB.

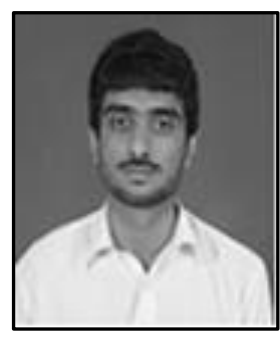

Muhammad Arifeen Ali, he is a student of MS at US-PAK Centre for Advance studies in Energy, NUST. He has completed his BS Electrical Engineering from CIIT.

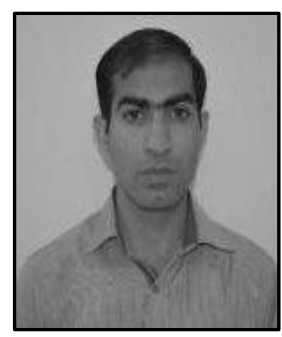

Asim Waris, he did his master's degree from National University of Sciences and Technology (NUST) in Mechanical Engineering. He did his bachelors from EME College NUST in Mechatronics Engineering. Currently $\mathrm{He}$ is $\mathrm{PhD}$ student at University of Alborg, Denmark. 